\title{
DEVELOPMENT OF RAW AND TREATED FLAX STRAW FOR OIL SPILL CLEANUP
}

\author{
Pooya Ghasemi, Duncan Cree \\ Department of Mechanical Engineering \\ University of Saskatchewan \\ ( pooya.ghasemi@usask.ca), ( duncan.cree@usask.ca )
}

\author{
Alvin Ulrich \\ Biolin Research Inc. \\ Saskatoon, Canada \\ ( aulrich@biolin.sk.ca)
}

\begin{abstract}
An oil spill is a critical problem and appears to have increased in the number of incidence over the past decade. There are several methods for oil spill cleanups. One method is called sorption using either synthetic or natural sorbents. Synthetic sorbents are harmful to the environment as they create another form of waste for nature. This gives rise to evaluate a more environmentally friendly natural sorbent. This research represents the results of study carried out to evaluate the effect of chemical treatment (acetylation) on properties of flax straw as a natural fiber. Sorption capacity of untreated and chemically treated flax straw was examined. It was found that performing the acetylation treatment on flax straw, significantly increases oil sorption capacity in both light and heavy oil by $41 \%$ and $22 \%$ respectively and also decreases their water uptake by $5 \%$. Moreover, by decreasing the particle size (to $0.6 \mathrm{~mm}$ ) of the chopped flax straw, the oil sorption capacity increases. This research contributes to a greater understanding of flax straw properties for potential remediation and reclamation applications, representing the possibility of turning the available waste material into a valuable oil sorbent.
\end{abstract}

Keywords ; flax straw, treated straw, oil spill, cleanup, remediation.

\section{INTRODUCTION}

Our planet has enormous resources of oil and gas deep under its surface which is economically important in all parts of our lives. Every day, a portion of this valuable material is drawn out of the earth using modern machinery by thousands of oil and gas companies. At the same time, the number of related oil spill incidents are rising and therefore more research is required in oil spill cleanup [1].

So far, various methods are used in different circumstances, including sorption methods. Sorbents are either synthetic or natural. Although manufactured sorbents are high in sorption rate, they create another form of waste after application [2]. This is the main reason why studying natural sorbents are important. Most of the plants consist of fibers which are found to be a reliable oil sorbent [3]. Among them, the flax plant which is widely available across the province of Saskatchewan consists of a large number of fibers [4]. In Canada, flax is mainly cultivated because of its linseed oil and after the extraction of the oil seed the remaining plant is left to decompose in the field or burned. To develop an oil sorbent using this biomass, the first approach can be to extract the fibers from the plant's stem. Based on studies, flax fiber can adsorb up to 30 grams of oil per gram of the fibers which is considerable [4]. However, the process of removing fibers from the plant straw is time consuming and costly which would not be suitable for a low-cost oil sorbent.

The second proposal, which is the basis of the current study, is to develop an oil sorbent using the stem of flax plant commonly referred to as flax straw. To improve oil sorption and reduce water uptake, a chemical acetylation treatment was performed on the sample and the change in oil sorption characteristics was observed. Based on observed results, the acetylation method was found to increase the oil sorption capacity of flax straw while decreasing the water uptake.

\section{EXPERIMENTAL}

\section{A. Materials}

Flax straw from bales was supplied by Biolin Research Inc., a local company researching on development and application of value-added products from flax plant in Saskatoon, Canada. Flax received from the manufacture had a packing density of 220-310 g/L. Two types of oil were selected and purchased from Fisher Scientific based on ASTM F726 - 17, and ASTM F716 - 07. Light oil had a density range of $0.820 \mathrm{~g} / \mathrm{cm}^{3}$ to $0.870 \mathrm{~g} / \mathrm{cm}^{3}$, while heavy oil had a density range of 0.930 $\mathrm{g} / \mathrm{cm}^{3}$ to $1.000 \mathrm{~g} / \mathrm{cm}^{3}$. For acetylation, acetic acid and $\mathrm{N}$ Bromosuccinimide (NBS) were provided by Fisher Scientific.

\section{B. Raw Flax Straw Oil Sorbent Preparation}

A batch of flax straw was washed with distilled water, weighted and put in the oven at $60{ }^{\circ} \mathrm{C}$ for $24 \mathrm{~h}$. After $24 \mathrm{~h}$, the samples were reweighted to calculate the moisture content. After oven drying the batch of flax straw was chopped using the Retsch knife milling machine. The gap between the knife 
and cutting bar was adjusted to $1 \mathrm{~mm}$ and the opening of the output screen was $8 \mathrm{~mm}$ (Fig. 1). An outline of the experimental procedure is illustrated in Fig. 2.

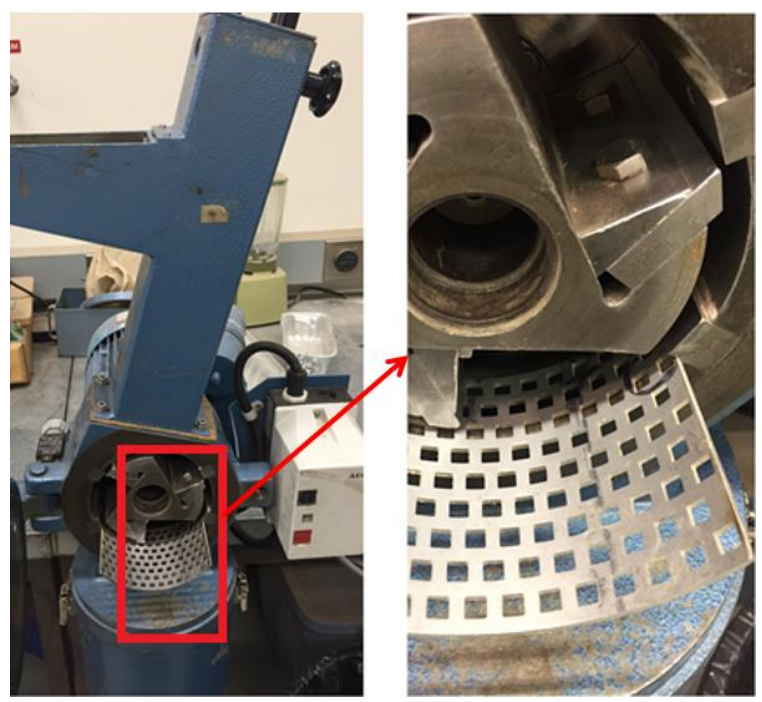

Figure 1. Chopping machine used for cutting the flax straw.

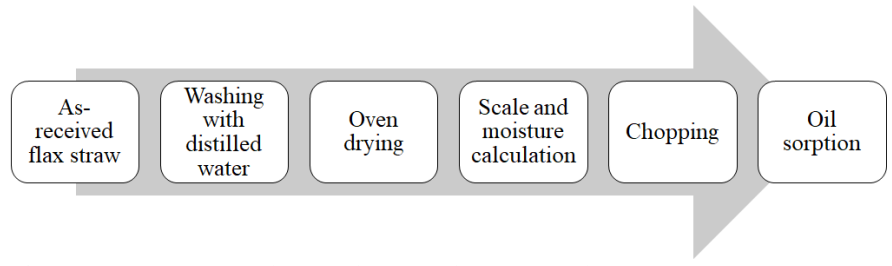

Figure 2. Experimental procedure for flax straw oil sorption test.

\section{Characterization of Flax Straw}

Three-dimensional imaging and viewing of the surface morphology for the as received flax straw was conducted using scanning electron microscopy (SEM) model JEOL JSM6010 LV (Tokyo, Japan). Images were taken at a low operating voltage of $5 \mathrm{kV}$ to prevent samples from burning (Fig. 3).

At this stage, a dried batch of flax straw was sieved based on the ASABE Standard S424.1: method of determining and expressing particle size of chopped forage material by screening. The opening size of the series of sieves used in this study was $3.3,2.3,1.6,1.1,0.8$ and $0.6 \mathrm{~mm}$.

\section{Acetylated Flax Straw Oil Sorbent Preparation}

For the acetylated samples, 15 grams of sieved material with a size less than $0.6 \mathrm{~mm}$ was chosen. The samples were placed in a flask containing $300 \mathrm{~mL}$ acetic anhydride and $1 \%$ NBS. The container was then placed in an oil bath at $100{ }^{\circ} \mathrm{C}$ for $1 \mathrm{~h}$ as was proposed for a similar natural plant sugarcane bagasse [5]. After the reaction was completed the samples were removed from the container, washed with ethanol and acetone multiple times to remove any remaining by-products. The samples were then oven dried at $60{ }^{\circ} \mathrm{C}$ for $12 \mathrm{~h}$.

\section{E. Oil Sorption Experiment}

The sorption characteristics of raw and treated flax straw were evaluated with light and heavy oil. To understand the relation of particle size and sorption capacity, the experiments were performed on light and heavy oil for different particle sizes. Based on ASTM F726 - 17 the sorbent was considered of Type II (loose sorbent). Each sample had an approximate minimum weight of 4 grams. To begin the test, flax straw samples were put in a rectangular stainless-steel Mesh No.20 ( $0.841 \mathrm{~mm}$ opening) basket having dimensions of $4 \times 9 \times 7 \mathrm{~cm}^{3}$ (length $\mathrm{x}$ width $\mathrm{x}$ depth). Since the sorbent is of the loose type, the basket should have enough space for sorbent to freely float within the test cell. The rectangular basket was then lowered into the $1000 \mathrm{~mL}$ beaker containing $200 \mathrm{~mL}$ light or heavy oil. After 15 minutes of soaking the basket was removed from the beaker and hung for 30 seconds allowing excessive oil to drain. The sample was then removed from the basket and the experiment weight was recorded. Standard deviation considered for this experiment was $15 \%$ and each experiment was repeated three times. The weight of adsorbed oil was calculated by subtracting the weight of dry sorbent before the experiment from its weight after the experiment. Oil sorption capacity of samples were calculated using (1).

$$
\text { oil sorption }=\frac{\text { weight of adsorbed oil }}{\text { weight of sorbent }}
$$

\section{F. Water Uptake Experiment}

The proposed experiment for water uptake calculations is as follows: each trial test utilized approximately 5 grams of raw or treated flax straw. Samples with different sizes were placed in a $200 \mathrm{~mL}$ beaker and distilled water was added until they were completely submerged for 10 minutes. The samples were removed from the water and placed into a basket to hang for 5 minutes in order to release excess water. Finally, the sample were weighed. The amount of water uptake was calculated by subtracting the dried sample weight from wet sample weight.

\section{RESULTS AND DISCUSSION}

SEM was used to observe the morphology of the flax straw. As shown in Fig. 3 (c) there are several layers in a single flax straw structure. Each of them consists of a primary thin layer which contain both cellulose and hemicellulose [6]. The flax stem consists of two main parts; fiber and non-fiber part. The non-fibrous, soft spongy part is also called shives.
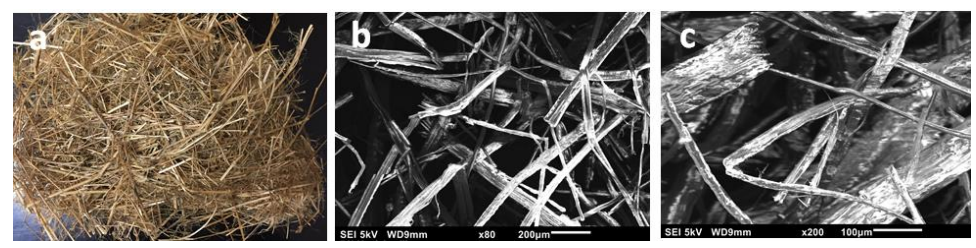

Figure 3. Images of purified and dried flax fiber or straw (a) macroscopic (b) 
and (c) SEM with magnification of 50X and 200X, respectively.

In Fig. 4 the content of the sieved material with openings of $3.3 \mathrm{~mm}$ is compared to the sieve with $0.6 \mathrm{~mm}$ openings. The combination of shives and fiber is more homogenous in the smaller mesh size compared to the larger size.
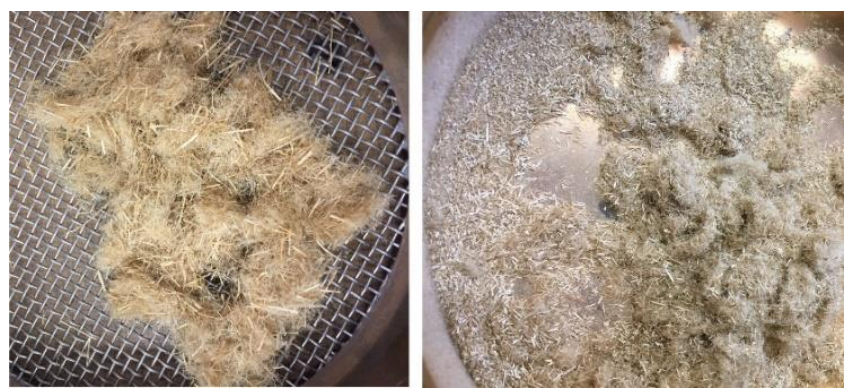

Figure 4. Comparison between the content of two different mesh sizes.

Different sieves used in this experiment are shown in Fig 5. The weight of particles trapped within each sieve is calculated as well as the mass ratio of each size category.

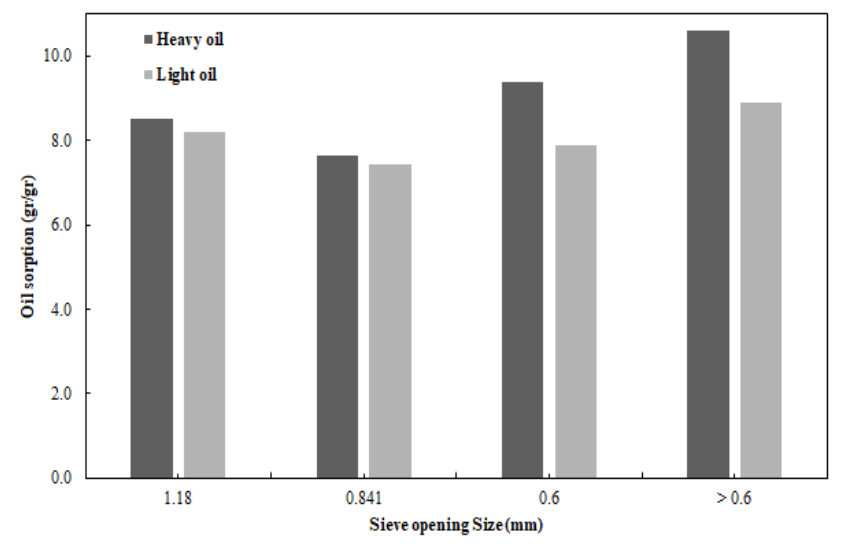

Figure 5. Comparison between oil sorption of the raw sample in light oil and

heavy oil.

The result illustrates a steady increase in oil sorption capacity of raw flax from $7.6 \mathrm{~g} / \mathrm{g}$ to $10 \mathrm{~g} / \mathrm{g}$ while the particle size of the samples decreased from $0.841 \mathrm{~mm}$ to $0.6 \mathrm{~mm}$, respectively. Although decreasing the particle size of the flax straw increases oil sorption capacity, it is expected that decreasing the size to $0.6 \mathrm{~mm}$ or smaller, will decrease the capacity due to lack of void spaces [7]. However, for sizes larger than $1.6 \mathrm{~mm}$, the experiment did not successfully pass the test requirement of being in a range of $15 \%$ deviation and the acquired results had many fluctuations. This can be explained by having less homogenous combination of fibers and shives in higher sieve sizes compared with smaller sizes which agrees with results shown in Fig. 4.
Fig. 6 compares the oil sorption capacity of raw and treated sample for sizes $0.6 \mathrm{~mm}$. Acetylated samples show a slightly higher oil sorption capacity which is probably due to the higher capillary forces between plasticized cellulose fibers and oil. More importantly, acetylated samples revealed less water uptake compared to untreated samples. This is due to the chemical modifications where the hydroxyl groups on the surface of fiber are replaced with acetyl groups. Upon this modification the properties of the fiber changed, and they became hydrophobic.

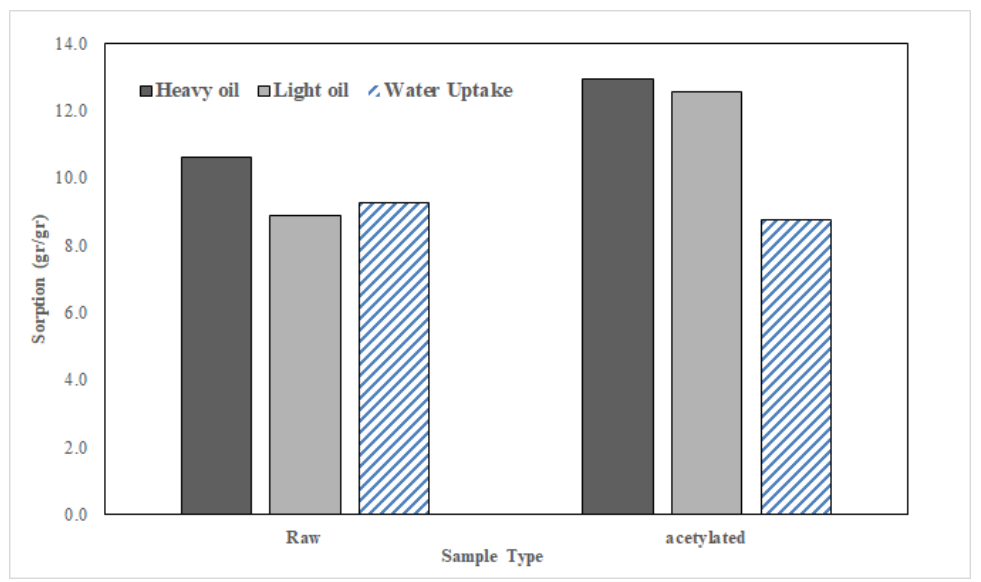

Figure 6. Comparison between the sorption capacity of the raw sample in light oil with heavy oil.

\section{CONCLUSIONS AND FUTURE WORK}

A new method for water and oil sorption was developed using flax straw where different physical and chemical treatment was performed on this material and the oil and water uptake properties was shown to improve.

1. It was found that the combination of shives and fiber is more homogenous in the smaller mesh size compared to the larger size which is an important consideration prior to performing oil sorption experiment.

2. The oil sorption results revealed an increase in oil sorption capacity up to $11 \mathrm{~g} / \mathrm{g}$ with decreasing particle size to $0.6 \mathrm{~mm}$.

3. Chemical modification changed the sorption properties of flax straw where the chemically treated samples showed an increase in oil sorption capacity by $41 \%$ and $22 \%$ in light oil and heavy oil, respectively. Also, the water uptake was reduced by $5 \%$ in chemically modified samples which is related to changes in surface properties (such as functional groups) of flax straw.

4. In conclusion, to address the use of sustainable sorbents, this study showed that a natural sorbent material made of waste flax straw obtained from the oil seed industry in Saskatchewan could be used as an oil spill cleanup material. 
Future testing to support this study will involve investigation of oil sorption properties of fibers in a media where both water and oil are presented at same time. Another important consideration would be investigation reusability and flammability of sorbent.

\section{ACKNOWLEDGMENTS}

The authors would like to acknowledge the support of the Department of Chemistry at University of Saskatchewan in assistant with performing acetylation setup. The authors express their gratitude to Alvin Ulrich for helpful discussions and the supply of the flax straw.

\section{REFERENCES}

[1] E. Quintana-Rizzo, Ester, J. J. Torres, S. W. Ross, I. Romero, K. Watson, E. Goddard, and D. Hollander., " ${ }^{15} \mathrm{~N}$ and $\delta^{13} \mathrm{C}$ in deepliving fishes and shrimps after the deepwater horizon oil spill, Gulf of Mexico," Mar. Pollut. Bull., vol. 94, pp. 241-250, 2015.

M. O. Adebajo, R. L. Frost, J. T. Kloprogge, O. Carmody, and S.
Kokot, "Porous materials for oil spill cleanup: A review of synthesis and absorbing properties," J. Porous Mater., vol. 10, no. 3. pp. 159$170,2003$.

[3] H. M. Choi and R. M. Cloud, "Natural sorbents in oil spill cleanup," Environ. Sci. Technol., vol. 26, no. 4, pp. 772-776, 1992.

[4] I. A. Ansari, G. C. East, and D. J. Johnson, "Structure-property relationships in natural cellulosic fibres: Part III: Flax-an oil sorbent.," J. Text. Inst., vol. 94, no. 1-2, pp. 1-15, 2003.

[5] X. F. Sun, R. C. Sun, and J. X. Sun, “Acetylation of sugarcane bagasse using NBS as a catalyst under mild reaction conditions for the production of oil sorption-active materials," Bioresour. Technol., vol. 95, no. 3, pp. 343-350, 2004.

[6] M. Z. Rong, M. Q. Zhang, Y. Liu, G. C. Yang, and H. M. Zeng, "The effect of fiber treatment on the mechanical properties of unidirectional sisal-reinforced epoxy composites," Compos. Sci. Technol., vol. 61, no. 10, pp. 1437-1447, 2001.

[7] R. Behnood, B. Anvaripour, N. J. H. Fard, and M. Farasati, "Petroleum hydrocarbons adsorption from aqueous solution by raw sugarcane bagasse,” Int. J. Emerg. Sci. Eng., vol. 1, no. 6, pp. 9699, 2013 